\title{
A coughing, tiptoeing six-year-old
}

Benjamin O Adeyemi

CASE

A woman brought her previously well son, aged six years, to the general practitioner (GP) because he had been having difficulties with walking over the previous three days. This had been preceded by a four-day history of cough, fever and coryza, which was followed by generalised muscle aches that eventually settled in the calves. The calf pains, which were usually worse in the morning, became so severe that he was crawling on all fours over the following two days. However, on the third day, he was able to walk on tiptoes.

There was no history of travel, trauma, sore throat, rash, diarrhoea or respiratory difficulties. There was no personal or family history of neuromuscular diseases. His routine vaccinations were up to date.

Clinically, the boy was alert and had a tiptoe gait. His vital signs, cardiorespiratory and spinal examinations were unremarkable. He had bilateral tender calf muscles with normal lower limb range of motion, tone, power, sensation and deep tendon reflexes.

Office-based examination of his urine was normal.

\section{Question 1}

What is the most likely diagnosis? What important differential diagnoses should be considered in this case?

\section{Question 2}

What are the causes of this condition?

\section{Question 3}

Which tests are required to establish a diagnosis?

\section{Question 4 \\ What are the complications?}

\section{Answer 1}

The presentation is consistent with a diagnosis of benign acute childhood myositis (BACM).

The actual incidence of BACM is uncertain. ${ }^{1-3}$ It is, however, increasingly being recognised as an often-missed cause of childhood lower leg pain..$^{1-3}$ BACM is usually seen in school-aged children recovering from viral upper respiratory tract infection (URTI), ${ }^{4,5}$ hence the synonyms viral myositis and influenzaassociated myositis. ${ }^{1,5}$ It is more common in boys. ${ }^{6,7}$ BACM classically manifests as acute-onset, bilateral leg pain largely confined to the gastrocnemius and soleus muscles. ${ }^{1,4,5}$ This causes a sudden inability to bear weight and/or walk, resulting in tiptoeing or stiff-legged gait. ${ }^{5}$

The differential diagnoses to consider in BACM include: ${ }^{2,3,5}$

- non-specific myalgia

- Guillain-Barré syndrome

- trauma or non-accidental injuries with fractures

- dermatomyositis

- transient synovitis

- infections (osteomyelitis/septic arthritis)

- deep venous thrombosis

- malignancy

- juvenile idiopathic arthritis.

\section{Answer 2}

Influenza type A and B viruses are most often implicated. ${ }^{5}$ Influenza type $B$ is responsible for the majority of cases. ${ }^{4,5}$

\section{Answer 3}

The characteristic manifestations of BACM often allow for diagnosis on clinical grounds. ${ }^{1}$ Unfamiliarity with
BACM may cause confusion with serious conditions, resulting in inappropriate invasive tests and hospitalisation..$^{3,4}$ This is particularly relevant for the office GP, as most reported cases of BACM have been diagnosed in paediatric, in-patient and emergency department settings. ${ }^{2-7}$

Serum creatine kinase levels and viral studies may be used to confirm the diagnosis ${ }^{2}$ but are not necessary in straightforward cases. In rare severe cases, investigations are used to exclude complications or other sinister differentials. ${ }^{4}$ The most frequently reported laboratory abnormality is transient creatine kinase elevation ${ }^{2,4}$ with normalisation within two weeks. ${ }^{5}$ Leukopenia and elevated level of aminotransferases may also be found. ${ }^{4}$

\section{Answer 4}

Rhabdomyolysis with acute renal failure is a rare but serious complication ${ }^{2}$ that must be excluded in patients who report passing dark urine ${ }^{3}$ or with rapidly worsening symptoms or who fail to recover in a few days. ${ }^{2}$

\section{CASE CONTINUED}

The patient's mother was advised about the diagnosis, its expected course and the need to seek urgent clinical review if there was passage of dark urine or unexpected progressive muscle weakness. Requests for full blood count, creatine kinase and influenza virus polymerase chain reaction testing on nasopharyngeal swab were sent with a scheduled clinic review in 72 hours.

At follow-up 72 hour later, the boy was still coughing but otherwise well. His calf pains had resolved, and he had started walking normally the day before. His results are as shown in Table 1. 


\section{Question 5}

What is the usual treatment for this condition?

\section{Question 6}

What is the prognosis?

\section{Question 7}

How can BACM be prevented?

\section{Answer 5}

Outpatient management with analgesics ${ }^{1,8}$ and safety-netting advice ${ }^{3,8}$ is usually sufficient.

\section{Answer 6}

Despite the frightening presentations, BACM is self-limiting, with full recovery ${ }^{4,8}$ expected over a median duration of three days. ${ }^{2}$ Alternative diagnoses should be considered in patients who fail to improve accordingly. ${ }^{1}$

\section{Answer 7}

The association between influenza vaccination and risk of BACM is unknown. ${ }^{5}$ Current evidence suggests that influenza vaccination is the most potent intervention for preventing influenza illness and its complications. ${ }^{9}$

\section{CASE CONTINUED}

The family's experience of this illness and media reports of the unusually severe influenza season at that time ${ }^{9}$ prompted a discussion on the benefit of influenza vaccination. The patient had never received influenza vaccination. Considering that the time of presentation was in late winter, the patient's mother chose to defer vaccinations until the following year.

\section{Key points}

- BACM should be part of the differential diagnoses in school-aged children who present with acute-onset bilateral calf pains and walking or gait difficulties while recovering from a viral URTI.

- In this setting, bilateral tenderness localised to the calves with normal neurology is reassuringly consistent with a diagnosis of BACM, safely excludes sinister differentials and requires no investigations.

- Familiarity with this dramatic but often benign condition enables clinicians to institute appropriate supportive management while avoiding unnecessary tests and hospitalisation.

\section{Author}

Benjamin O Adeyemi MBBS, DipHIVMan, DipPEC, MPH, MMed Fam Med, FCFP (SA), General Practitioner, Jema Clinic, Maryborough, Qld. ben_adeyemi@yahoo.com
Competing interests: None.

Funding: None.

Provenance and peer review: Not commissioned, externally peer reviewed.

\section{References}

1. Magee H, Goldman RD. Viral myositis in children. Can Fam Physician 2017;63(5):365-68.

2. Agyeman $P$, Duppenthaler $A$, Heininger $U$, Aebi $C$. Influenza-associated myositis in children. Infection 2004;32(4):199-203. doi: 10.1007/s15010-0044003-2

3. Terlizzi V, Improta F, Raia V. Simple diagnosis of benign acute childhood myositis: Lessons from a case report. J Pediatr Neurosci 2014;9(3):280-82. doi: 10.4103/1817-1745.147595.

4. Almeida Santos J, Albuquerque C, Lito D, Cunha F. Benign acute childhood myositis: An alarming condition with an excellent prognosis! Am J Emerg Med 2014;32(11):1418-19. doi: 10.1016/j. ajem.2014.08.022

5. Jain S, Kolber MR. A stiff-legged gait: Benign acute childhood myositis. CMAJ 2009;181(10):711-13. doi: 10.1503/cmaj.090781.

6. Rosenberg T, Heitner S, Scolnik D Levin Ben-Adiva E, Rimon A, Glatstein M. Outcome of benign acute childhood myositis: The experience of 2 large tertiary care pediatric hospitals. Pediatr Emerg Care 2018;34(6):400-02. doi: 10.1097/PEC.0000000000000830.

7. Oketah O, Okafor I, Deiratany S, McNamara R. G32(P) Benign acute childhood myositis: Clinical presentation in an emergency department. Arch Dis Child 2014;99(Suppl 1):A14-A5.

8. Whittington Health NHS Trust. Calf pain in children: A parent's guide. London: Whittington Health NHS Trust, 2014. Available at www. whittington.nhs.uk/document.ashx?id=4697 [Accessed 20 August 2017].

9. National Centre for Immunisation Research \& Surveillance (NCIRS). Influenza vaccines for Australians: Information for immunisation providers. Westmead, NSW: NCIRS, 2018. Available at www.ncirs.edu.au/assets/provider resources/fact-sheets/Influenza-fact-sheet.pdf [Accessed 2 June 2018].

Table 1. Patient's laboratory results and trends

\begin{tabular}{lccc}
\hline & Reference range & At presentation & Day 10 post-presentation \\
\hline Creatine kinase $(\mathrm{U} / \mathrm{L})$ & $30-150$ & 4197 & 214 \\
\hline White cell count $\left(\times 10^{9} / \mathrm{L}\right)$ & $6.0-15.0$ & 3.2 & 8.5 \\
\hline Neutrophils $\left(\times 10^{9} / \mathrm{L}\right)$ & $1.5-7.5$ & 0.88 & 4.53 \\
\hline $\begin{array}{l}\text { Lymphocytes }\left(\times 10^{9} / \mathrm{L}\right) \\
\begin{array}{l}\text { Influenza virus polymerase } \\
\text { chain reaction test }\end{array}\end{array}$ & $2.0-8.0$ & 1.71 & 3.06 \\
\hline
\end{tabular}

